нравственных, социально-культурных ценностей, принятых правил и норм поведения в обществе; формирование социально-культурной среды с учётом возрастных, психологических особенностей, а также интересов и желаний; реализация образовательной деятельности с привлечением социально-культурных возможностей.

Процесс развития совершается в рамках социально-культурного пространства путем приобщения студентов к культурным ценностям и особенностям.

Для создания оптимальных условий привлечения студентов в социальнокультурную деятельность необходимо провести анализ социально-культурной образовательной среды, определить основные задачи проекта, создать программу проведения социально-культурных мероприятий в вузе и обеспечить процесс самореализации студентов. Запуск механизма социально-культурного пространства реализуется за счет определенного события (олимпиада, праздник, круглый стол, конференция), в котором технологическим моментом является совместная деятельность студентов.

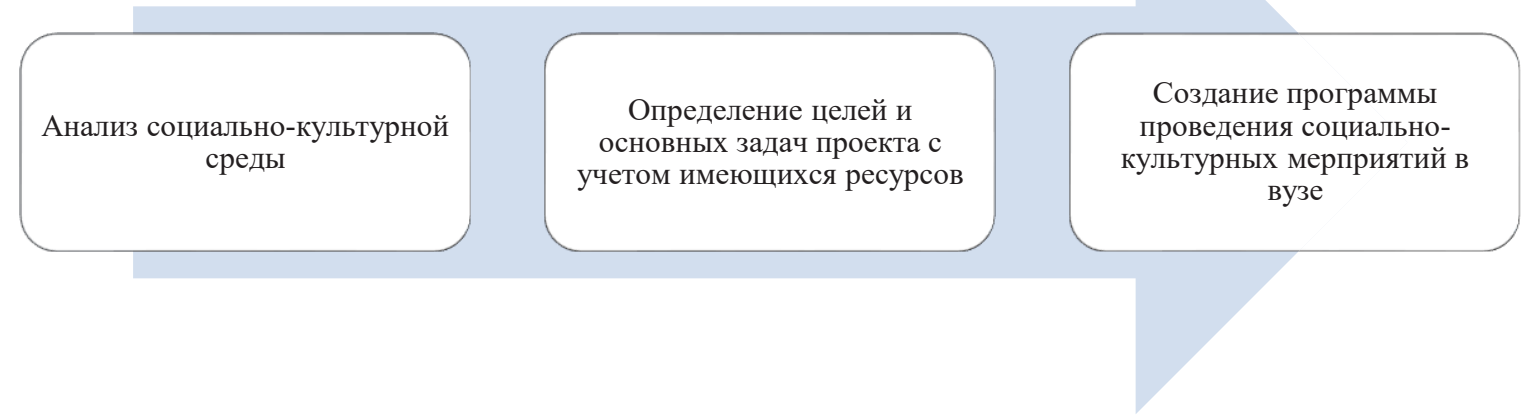

Рисунок 2. Ключевые этапь создания оптимальных условий для реализациии соџиально-культурной деятельности

Посредством данных мероприятий проходит духовное, физическое развитие обучающихся, развиваются ключевые навыки будущих специалистов, что доказывает важность социально-культурного сопровождения в высших учебных заведениях.

$$
* * *
$$

1. Николаева Г.Н. Социальное проектирование культурно-досуговой деятельности. М.: МАДИ, 2019. $-81 \mathrm{c}$.

2. Уколова Л.И. Влияние культурно-образовательной среды на процесс воспитания растущего человека//Мир науки, культуры, образования. 2013. № 6 (43). С. 274-276.

\title{
Чемерилова И.А. \\ Способы измерения адаптивных ресурсов семьи, воспитывающей ребенка с ограниченными возможностями здоровья
}

ФГБОУ ВО «ЧГУ им. И.Н. Ульянова»

doi: 10.18411/lj-04-2021-178

(Россия, Чебоксары)

Исследование выполнено при финансовой поддержке РФФИ в рамках научного проекта № 20-013-00765.

\section{Аннотация}

В статье рассмотрены возможные пути изучения адаптивных ресурсов родителей, воспитывающих детей с ОВ3, в условиях инклюзивных образовательных организаций. Предложен диагностический инструментарий, необходимый для 
проведения комплексного обследования и сопровождения данной категории семей, представлены результаты экспериментального исследования.

Ключевые слова: инклюзивная практика, изучение семьи ребенка с ограниченными возможностями здоровья, адаптивные ресурсы.

\section{Abstract}

The article discusses possible ways of studying the adaptive resources of parents raising children with disabilities in the context of inclusive educational organizations. The diagnostic tools necessary for the comprehensive examination and maintenance of this category of families are proposed, the results of an experimental study are presented.

Keywords: inclusive practice, studying the family of a child with disabilities, adaptive resources.

Инклюзивный подход в образовании связан с переосмыслением обществом и государством своего отношения к детям с ограниченными возможностями здоровья, с признанием не только равенства их прав, но и осознанием своей обязанности обеспечить таким детям полноценное образование. В современных условиях его полноценной реализации разработка научных подходов (методологических, методических, практических) к организации и осуществлению сопровождения семей, воспитывающих детей с ограниченными возможностями здоровья, является особо востребованной. В связи с этим исследование, направленное на выявление возможностей измерения адаптивных ресурсов семьи, воспитывающей детей с ограниченными возможностями здоровья, соответственно, с особыми потребностями, в условиях инклюзивного образования, представляется нам актуальным.

Адаптация семьи к процессу воспитания и сопровождения ребенка с ограниченными возможностями здоровья в жизненном пространстве представляет собой сегодня серьезную социальную и психологическую проблему. Жизнь большинства семей, в которых рождается такой ребенок, сопровождается целым рядом деструктивных переживаний, отсутствием моральной поддержки, несформированностью механизмов продуктивной адаптации к жизни. Многие из родителей и члены семьи сами нуждаются в социально-психологической и педагогической помощи.

Анализ научных источников по теме исследования позволяет нам констатировать, что проведено достаточно много исследований, посвященных данной теме: изучались проблемы психолого-педагогического сопровождения родителей детей с ограниченными возможностями здоровья [1,2]; пути формирования социальнопедагогических компетенций родителей[3]. Обобщен современный опыт в области сопровождения семей, воспитывающих детей с ОВ3, выделены основные трудности и проблемы, с которыми сталкиваются родители детей с особыми образовательными потребностями в условиях инклюзивного образования [4]. На основе анализа проблем инклюзивной практики актуализированы возможности развития компетенций родителей, воспитывающих детей с ограниченными возможностями здоровья, средствами комплексного сопровождения семей [5].

Успешная интеграция детей с ограниченными возможностями в образовательную среду зависит от ряда факторов, среди которых важнейшим является адаптационно-реабилитационный потенциал семьи. Под ним мы понимаем совокупность социально-психологических характеристик семьи, личностных особенностей родителей, способных полноценно содействовать разностороннему развитию ребенка, его успешной социализации, позитивной адаптации к жизнедеятельности в обществе и реабилитации.

Для характеристики адаптивных ресурсов исследуемой семьи имеет значение такой показатель, как адаптационно-реабилитационный потенциал. Данный показатель 
является важнейшим фактором, влияющим на степень успешности интеграции детей с ограниченными возможностями в образовательную среду

Адаптационно-реабилитационный потенциал семьи, воспитывающей ребенка с ограниченными возможностями здоровья, мы определяем как понимаем совокупность социально-психологических характеристик семьи, личностных особенностей родителей, способных полноценно содействовать разностороннему развитию ребенка, его успешной социализации, позитивной адаптации к жизнедеятельности в обществе и реабилитации.

Данный показатель находит выражение в следующих компонентах:

1) реабилитационной активности родителей, которая в свою очередь выражается в последовательной ориентации родителей на тесное взаимодействие со специалистами в целях успешной реабилитации и социальной адаптации ребенка; правильном представлении о нарушениях ребенка, способах его интеграции в обществе; активной позиции в отношении создания условий для его реабилитации; владение специальными знаниями и умениями ухода за ребенком;

2) психолого-педагогической компетентности родителей, выражающейся во владении полными знаниями и совершенными умениями, позволяющими реализовать на практике все необходимые развивающие мероприятия для ребенка; способности принимать ребенка таким, каков он есть, выстраивать с ним правильные взаимоотношения; высоком осознании родительской ответственности;

3) психологических характеристиках родителей, таких как уровень самооценки, преобладающее психоэмоциональное состояние, жизнестойкость, способность личности выдерживать стрессовую ситуацию выбора, удовлетворенность жизнью, мировосприятие в целом.

В ходе теоретического исследования были определены уровни адаптационнореабилитационного потенциала исследуемой семьи.

Для высокого уровня характерны ориентированность родителей на максимальное сотрудничество со специалистами по реабилитации, полное представление о дефектах в развитии ребенка; участие в разработке и обсуждении адаптивной образовательной программы, систематические занятия с ребенком, частые контакты с педагогами, психологом и социальным педагогом, овладение развивающими и коррекционными методиками для занятий с ребенком, активный поиск источников материальной и моральной помощи, необходимой для лечения, обучения и воспитания ребенка; высокий уровень жизнестойкости, то есть способность к оценке ситуации, своих возможностей, готовность активно и гибко действовать в ситуации выбора или трудностей; высокий уровень стрессоустойчивости, положительный микроклимат в семье, оптимальные конструктивные отношения между родителями и ребенком, эффективный стиль семейного воспитания.

Для среднего уровня характерны неполное представление родителей о дефектах в развитии ребенка; ознакомление с адаптивной образовательной программой, занятия c ребенком по адаптивной образовательной программе, недостаточно активное общение со специалистами; средний уровень жизнестойкости, характеризующий наличием периодов отчаяния, замкнутости, повышенной тревожности, неверия в свои возможности, критического отношения к себе, но в целом характерна активная жизненная позиция, умение сопротивляться трудностям, искать пути решения проблем; средний уровень стрессоустойчивости; неопределенный, сложный микроклимат в семье, явления гиперопеки, доминирования, сохранения дистанции, высокой требовательности в семейном воспитании.

Низкому уровню присущи: неадекватное представление родителей о дефектах в развитии ребенка, низкая мотивация в совместной с педагогами разработке и обсуждении адаптивной образовательной программы, отсутствие занятий с ребенком, 
редкое общение со специалистами по своей инициативе, пассивная позиция в отношении поиска источников материальной и моральной помощи для ребенка; низкий уровень жизнестойкости, то есть преобладание таких явлений, как замкнутость, закрытость, низкая самооценка, неверие в себя, комплекс вины, пессимистическое настроение, склонность к панике и разочарованию, неудовлетворенность жизнью, не сформирована способность к анализу и готовность искать пути решения проблем; низкий уровень стрессоустойчивости, устойчивый отрицательный психологический климат в семье, неконструктивные детско-родительские отношения, неэффективный стиль семейного воспитания.

В экспериментальном исследовании приняли участие 80 семей, воспитывающих детей с ограниченными возможностями здоровья, проживающих в Чувашской Республике.

Для выявления уровня реабилитационной активности родителей был составлен опросник, включавший изучение следующих вопросов: соблюдение оптимального режима дня ребенком; регулярность медицинского обследования, осведомленность о социальных гарантиях для ребенка и возможностях оказания социальной помощи; об особенностях развития ребенка, общение с консультантами и специалистами в области реабилитации; психолого-педагогическая компетентность родителей, степень владения необходимыми развивающими и коррекционными методиками; активность в поиске источников материальной и моральной помощи, необходимой для лечения, обучения и воспитания ребенка; степень знакомства с программой социальнопедагогического сопровождения и адаптивными программами обучения; участие в родительском сообществе (клубе), объединяющем родителей, воспитывающих детей с OB3.

По результатам обследования, высокий уровень реабилитационной активности присущ 41,7 \% опрошенных родителей, средний уровень $-46,7 \%$, низкий уровень $11,6 \%$ респондентов.

Для характеристики адаптационно-реабилитационного потенциала семьи важное значение имеет такой показатель, как удовлетворенность жизнью.

Для его измерения мы использовали опросник Н.Н. Мельниковой «Удовлетворенность жизнью», позволяющей оценить чувство удовлетворенность жизнью как субъективно переживаемое состояние, реакция на окружающую реальность. Признаками удовлетворенности или удовлетворенности при этом являются преобладающее эмоциональное состояние, активная (пассивная) жизненная позиция, чувство насыщенности или пустоты жизни, интерес к себе и окружающим, ощущение стабильности (нестабильности) существующей ситуации и др. В процессе обследования родителям было предложено 46 вопросов опросника. Ответ на каждый вопрос оценивался в баллах.

Человек с высоким значением удовлетворенностью жизнью характеризуется позитивным мировосприятием, ощущением полноты жизни, способностью адаптироваться к определенным обстоятельствам, умением общаться, проявлять нравственные чувства, сострадать и помогать другим людям, принимать себя и окружающих такими, каковы они есть, активной жизненной позицией, умением находить выходы из проблемных ситуаций, стойко переносить жизненные лишения.

Люди с низким значением этого показателя отличаются повышенной тревожностью, замкнутостью, низкой самооценкой, неверием в свои возможности, закрытостью. Им часто присуще пессимистическое настроение, склонность к панике и разочарованию, неудовлетворенность своей жизнью, ощущение пустоты жизни, ее безысходности, постоянная усталость, неумение строить жизненные перспективы и целеустремленно стремиться к ним. Они не имеют ощущения полноты жизни, с трудом преодолевают жизненные трудности; часто не способны к позитивной адаптации в изменившихся жизненных обстоятельствах, сосредоточены на поиске 
виновных, в том подвержены «самокопанию» и самобичеванию, не способны принимать себя такими, каковы они есть.

Тест «Удовлетворенность жизнью» включает взаимосвязанные между собой шкалы, которые обозначены как «факторы»: «жизненная включенность», «разочарование в жизни», «усталость от жизни», «беспокойство за будущее». Каждый фактор имеет три уровня выраженности: высокое значение, среднее и низкое значение. Показатель удовлетворенностью жизнью в целом складывается из суммы показателей для каждой из четырех субшкал.

По результатам исследования, высокий уровень удовлетворенностью жизнью наблюдался у $23,5 \%$ респондентов; средний уровень - у $35,3 \%$, низкий уровень почти у 41,2\% опрошенных родителей. Мы полагаем, что наличие ребенка с OB3 в семье влияет на субъективное восприятие личностью степени своего ощущения жизни.

Для измерения стрессоустойчивости целесообразно использовать: 1) опросник, определяющий склонность к развитию стресса (по Т.А. Немчину и Тейлору); 2) методику «Оценка эмоционально-деятельностной адаптивности» по Н.П. Фетискину, В.В. Козлову, Г.М. Мануйлову; 3) методику «Оценка нервно-психического напряжения» (Т.А. Немчин); 4) шкалу психологического стресса PSM-25 (адаптация Н.Е.Водопьяновой).

В нашем исследовании мы диагностировали уровень стрессоустойчивости у родителей с помощью Опросника, определяющего склонность к развитию стресса (по Т.А. Немчину и Тейлору) и выявили, что высокий уровень измеряемого качества присущ 36,7 \% испытуемых, средний уровень - 48,3\%, низкий уровень - 15\% респондентов.

Исследование психологического климата в семье было проведено с помощью Теста «Биополе семьи», состоящего из 35 утверждений, с которыми родители должны были согласиться или не согласиться.

Под психологическим климатом семьи в нашем исследовании понимается совокупность таких компонентов, как преобладающие в семье отношения друг к другу, стиль и характер общения, субъективное ощущение собственной социальной значимости и возможность реализации личностного потенциала для каждого члена семьи, преобладающие способы решения спорных вопросов, поведение в конфликтных ситуациях, выраженность чувств защищенности и эмоциональной удовлетворенности.

Обработка данных осуществлялась по «ключу» и позволила выделить 4 типа психологического климата в диапазоне от «устойчивого положительного» до «устойчивого отрицательного». 20\% опрошенных родителей оценили климат в своей семье как устойчивый положительный. Для такого климата характерны атмосфера единения, душевного тепла, поддержки, любви и доверия друг к другу. В семье с устойчивым положительным психологическим климатом члены семьи испытывают чувства собственной ценности и значимости, защищенности и эмоциональной удовлетворенности, заинтересованы в общении, совместных делах, стремятся проводить свободное время в домашнем кругу. 40\% респондентов оценили психологический климат в семье как неустойчивый, переменный, для которого характерны чередование благоприятной картины в отношениях и периоды ссор и конфликтов, напряжения в отношениях, отсутствия взаимопонимания в житейских вопросах. 23,3\% опрошенных родителей определили психологический климат в своей семье как неопределенный, сложный, неоднозначный, для которого характерны затяжные негативные явления, однако в целом преобладают позитивные тенденции.

Устойчивый отрицательный психологический климат отмечается в семьях, где преобладают такие явлениями, как постоянные ссоры, хронический стресс, тревожность, эмоциональный дискомфорт, отчуждение. Наличие такого климата отметили $16,7 \%$ родителей. 
Измерение адаптивных ресурсов семьи является важнейшим направлением работы с семьей в условиях инклюзивной практики и основанием для психокоррекционной работы с родителями. Психологическую помощь родителям сегодня оказывают Центры диагностики и консультирования, психологопедагогической реабилитации и коррекции, с которыми должны поддерживать образовательные организации, где обучаются дети с ОВ3.

1. Кашинская О.В. Комплексное сопровождение семей, воспитывающих детей с ограниченными возможностями здоровья и инвалидностью в условиях инклюзивной образовательной организации // Вестник науки и образования. 2017. - №5 (29). - Том 2. - С 97-100.

2. Пазухина С.В., Калинина 3.Н., Декина Е.В. Психолого-педагогическое сопровождение родителей детей с ограниченными возможностями здоровья //Гуманитарные науки. - 2018. - № 2. - С.128 136.

3. Чемерилова И.А., Иванова Е.К. Исследование возможностей формирования социальнопедагогических компетенций родителей, воспитывающих детей с ограниченными возможностями здоровья, в условиях инклюзивной практики // Современная система образования: опыт прошлого - взгляд в будущее. Актуальные вопросы пенитенциарной и вузовской педагогики//Сб. науч. тр. Чебоксары: Изд-во ЧГУ, 2018. - С.161-167.

4. Чемерилова И.А., Иванова Е.К. Современная практика сопровождения семей, воспитывающих детей с ОВ3 // Мир науки, культуры, образования. - 2020. - №4 (83). - С. 203-205.

5. Чемерилова И.А., Кириллова О.В., Кириллова Т.В. Формирование компетенций родителей, воспитывающих детей с ограниченными возможностями здоровья // Глобальный научный потенциал. - № 4 (109). - С. 87-89.

\section{Чжу Ченхуэй, Минакова Л.Ю. \\ Методы устранения влияния временных и пространственных факторов на межкультурную коммуникацию в поликультурной среде}

Томский государственный университет (Россия, Томск)

doi: 10.18411/lj-04-2021-179

\section{Аннотация}

В статье анализируются два фактора, определяющих невербальное общение время и пространство - с точки зрения межкультурной коммуникации в процессе иноязычного общения между российскими и китайскими студентами. Подчеркивается важная роль этих двух факторов в решении проблем межкультурного барьера, возникающего в результате культурных различий. В статье выделены культурные причины этих различий, вызванные историческими и бытовыми обстоятельствами, традициями и обычаями двух стран. Учет выделенных невербальных аспектов коммуникации при реализации межкультурного общения помогает повысить его результативность. Использование метода ситуативного общения языковых партнеров позволяет снизить влияние факторов времени и пространства на межкультурную коммуникацию.

Ключевые слова: межкультурная коммуникация, невербальная коммуникация, время, пространство.

\section{Abstract}

Two factors that determine non-verbal communication - time and space - from the point of view of intercultural communication in the process of foreign language communication between Russian and Chinese students are analyzed in this paper. The important role of these two factors in solving the problems of the intercultural barrier arising as a result of cultural differences is emphasized. The article highlights the cultural reasons for these differences caused by historical and everyday circumstances, traditions and customs of 